\title{
O PET-QUIZ COMO DIFUSOR DE CONHECIMENTO ACERCA DAS ÊNFASES ABORDADAS NA GRADUAÇÃO EM ENGENHARIA CIVIL
}

Gabriel de Carvalho Neves - gabrielneves.dc@gmail.com

Universidade Federal do Pará

R. Augusto Corrêa, 01 - Guamá

66075-110 - Belém - Pará

Gabriel Melém Maués-gmelemm@gmail.com

Universidade Federal do Pará

R. Augusto Corrêa, 01 - Guamá

66075-110 - Belém - Pará

Marivana Figueredo de Almeida - marivanafa@gmail.com

Universidade Federal do Pará

R. Augusto Corrêa, 01 - Guamá

66075-110 - Belém - Pará

Camila Silva Pina - camila.pina2000@gmail.com

Universidade Federal do Pará

R. Augusto Corrêa, 01 - Guamá

66075-110-Belém-Pará

Nívea G B Albuquerque-nivea@ufpa.br

Universidade Federal do Pará

R. Augusto Corrêa, 01 - Guamá

66075-110 - Belém - Pará

Resumo: Este estudo apresenta uma competição semestral elaborada pelo Programa de Educação Tutorial (PET) Engenharia Civil da UFPA, denominada PET-Quiz, que trata sobre os conhecimentos gerais de engenharia numa dinâmica de perguntas e respostas, na intenção de apresentar as grande ênfases da Engenharia Civil aos calouros desde o início do curso, transcendendo ao ambiente de educação formal, de forma a estimular o desenvolvimento de habilidades, que incluem o desenvolvimento de pensamento crítico, comunicação $e$ colaboração. Em sua $4^{\circ}$ edição, apresentou novo formato, com linguajar simplificado, tom e dinâmica diferenciados, visando seguir o gênero televisivo de programa de auditório, idealizado para que os alunos pudessem competir de forma animada em equipes. Através de sorteio, as equipes receberam as questões nas diferentes áreas temáticas da engenharia, a saber: Construção Civil, Estruturas, Materiais, Geotecnia, Transportes e Hidrotecnia. Ao final da competição, as equipes foram incentivadas a preencherem um formulário online, o qual tinha como principal objetivo analisar o impacto do PET-Quiz sobre os conhecimentos prévios acerca das principais áreas segmentadas pelo curso, assim como a possível mudança de perspectiva dos estudantes em relação pretextos da sua formação acadêmica. Com tais dados, foi possível analisar a eficiência do PET-Quiz na difusão dos conhecimentos teóricos das 
"Os desafios para formar hoje o engenheiro do amanhã"

grandes áreas do curso aos calouros, o qual se mostrou eficaz. Percebe-se, também, que as perspectivas que os participantes outrora tinham em relação ao ingresso na graduação alteraram-se por uma parcela dos entrevistados.

Palavras-chave: Engenharia Civil. Integração. Metodologia Ativa. PET.

\section{INTRODUÇÃO}

Durante o processo de entrada no curso de Engenharia Civil na Universidade Federal do Pará (UFPA), os calouros contam com a Semana do Calouro, a qual oferece uma programação de acolhimento, apresentação e integração desses alunos ao meio acadêmico. Durante essa programação, o grupo do Programa de Educação Tutorial (PET) de Engenharia Civil da UFPA realizou a atividade PET-Quiz, uma dinâmica de competição de perguntas e respostas em equipes.

Foi preparada uma edição especial para este evento, uma vez que a edição convencional é composta de perguntas de nível técnico, destinada a alunos já em fase avançada na graduação. Nesta edição especial, o foco concentrou-se em difundir o conhecimento acerca das grandes áreas da graduação entre os calouros. As perguntas foram divididas entre as principais ênfases da graduação em Engenharia Civil e os calouros foram subdivididos em equipes. A apresentação das questões se deu por meio de projeção e as equipes respondiam, uma por vez, sendo a equipe ganhadora, a que acumulasse mais pontos durante a competição.

Figura 1 - Capa da apresentação do PET-Quiz, com abordagem semelhante à utilizada no gênero televisivo de programa de auditório

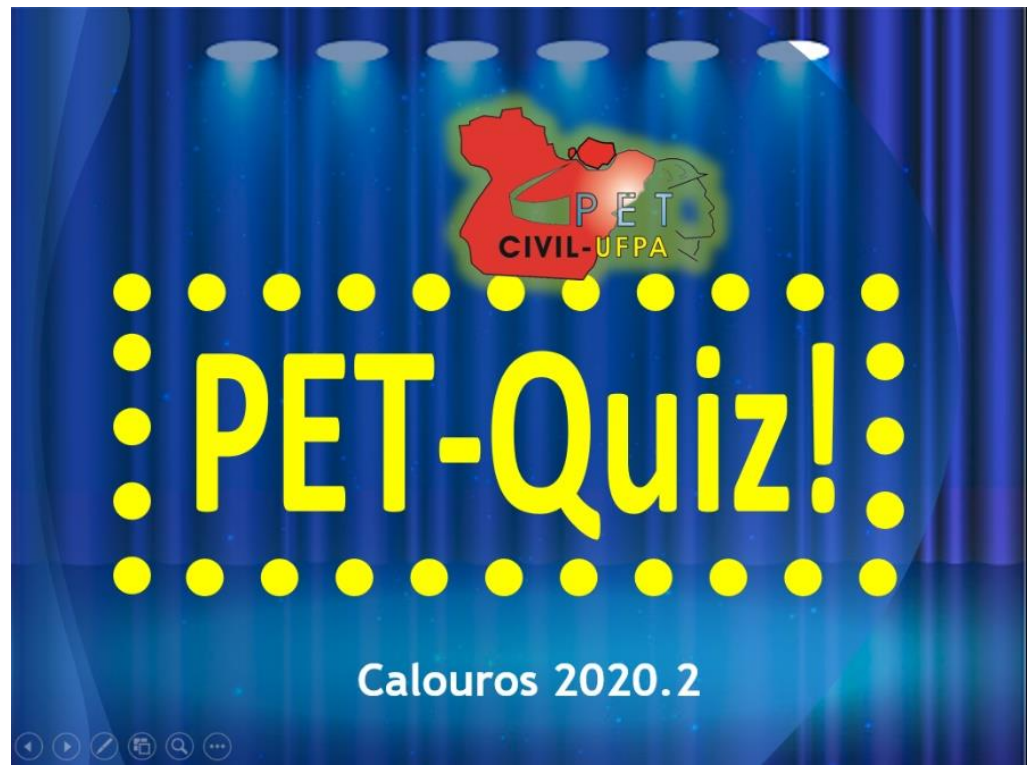


Após a execução da dinâmica, os participantes responderam a um questionário acerca do evento e das habilidades e conhecimentos adquiridos. A pesquisa adquiriu dados pertinentes à elaboração deste artigo. Ao preencherem todos os campos, os respondentes tiveram acesso ao certificado de participação no IV PET-Quiz, com carga horária de ensino de 4 (quatro) horas.

\subsection{Objetivo}

O presente artigo tem por objetivo analisar a eficiência do PET-Quiz em apresentar as ênfases abrangidas pelo curso de Engenharia Civil aos calouros e discutir se este proporcionou mudanças de perspectivas futuras sobre o curso.

\subsection{Metodologias Ativas}

O uso de metodologias ativas, em especial quizzes e competições, na disseminação do conhecimento causa estímulo aos participantes, permitindo um aprendizado mais duradouro (SANDE \& SANDE, 2018). No PET-Quiz, a finalidade de difundir o conhecimento das principais áreas da Engenharia Civil aos calouros ingressantes foi combinada ao uso dessa estratégia de ensino com sucesso, o que reforça a ideia de que, nos dias de hoje, professores e monitores devem buscar meios complementares de ensinamento (SILVA, J. M. A. et al, 2010).

Os jogos de quiz como o PET-Quiz devem ser preparados para o público a ser apresentado com diversos critérios.

"Para serem suficientemente convincentes, acreditamos que os jogos devem ser divertidos e desafiadores. Para produzir com sucesso um jogo divertido e desafiador, é necessário um extensivo teste do jogo e um investimento significativo (tempo e dinheiro) na produção e fabricação". (COIL. D. A. et al, 2017).

O uso do quiz como forma de difundir conhecimento deve ser adotado pela sua eficiência e possibilidade de continuidade, assim como afirma SILVA, J. M. A. et al (2010) "Dessa maneira, concluímos que o Quiz surge como um novo instrumento didático complementar, que pode ser constantemente atualizado e direcionado para as dificuldades encontradas, uma vez que o projeto pode ser continuado pelos ex-alunos da disciplina".

Ao colocar o ingressante frente ao questionamento sobre as características do curso de Engenharia Civil, permite-se tanto avaliar os fundamentos desse aluno sobre o assunto, quanto garantir com que ele aprenda sobre novas particularidades da área. Dentro do âmbito das metodologias ativas, o aprendizado baseado em problemas (Problem-Based Learning - PBL), por meio da prática de resolução de problemáticas, busca fazer com que os alunos em atividade consigam absorver informações ao se depararem com o teste que aborda novos conhecimentos (BARROWS; TAMBLYN, 1980).

Durante a atividade e a montagem de equipes para responder às questões propostas, criase um ambiente para que as decisões possam ser tomadas pelo grupo. Para que ocorra o processo de tomada de decisão, existe a necessidade da troca de conhecimentos prévios, por meio do debate, onde os alunos, de posse de seus entendimentos sobre as áreas da Engenharia Civil e das novas informações advindas da atividade, possam definir a alternativa correta de uma questão proposta, assumindo assim o caráter de continuidade no processo de aprendizagem (MILTRE, 2008). Tal proposta tem por finalidade o enriquecimento do perfil do aluno, a integração, além da generalização de conhecimentos que muitas vezes são abordados durante a graduação de forma técnica e centralizada. 


\subsection{Abordagem das áreas da Engenharia Civil e da grade curricular do curso}

Tradicionalmente, os cursos de Engenharia Civil são moldados seguindo as principais áreas de atuação na Engenharia Civil, como Construção Civil, Estruturas, Materiais, Geotecnia, Transportes e Hidrotecnia (CORDEIRO E SERRA, 2004). Entretanto, ao ingressar em uma universidade, nem todos os alunos possuem uma visão abrangente sobre as áreas de atuação que a habilitação no curso pode promover.

Tendo em vista que o processo de descoberta dessas ênfases somente ocorre com o decorrer das disciplinas estudadas, a apresentação do curso pode se tornar tardia e prolongada. Nesse intuito, a realização de atividades que inserem o aluno no contexto de conhecer com amplitude o curso de graduação em períodos iniciais tornam-se inerentes.

\subsection{Programa de Educação Tutorias (PET)}

O Programa de Educação Tutorial, dentre seus objetivos, seguindo os princípios da indissociabilidade acadêmica entre ensino, pesquisa e extensão, busca promover atividades acadêmicas em padrão de qualidade e contribuir para a formação de profissionais com elevada qualificação (BRASIL, 2010). Dessa maneira, os integrantes do programa, a fim de suprir essas incumbências, elaboram ações direcionadas tanto à sociedade em geral, como à comunidade acadêmica. Os estudantes capacitam-se frequentemente para a aplicação de capacitações e atividades e são direcionados por um Professor Tutor.

A atividade PET-Quiz trata de uma atividade destinada à comunidade acadêmica, no intuito de difundir e estimular o interesse pelas áreas abordadas pelo curso de Engenharia Civil. A atividade relatada no presente artigo, mais especificamente, consiste em uma adaptação para a realidade dos calouros do curso, com uma abordagem mais simplificada para que pudesse chegar o mais próximo possível das condições de resposta desses alunos, porém, mantendo o cunho de exposição das ênfases abordadas durante a graduação.

\section{METODOLOGIA}

Para analisar a relevância do PET-Quiz em disseminar o conhecimento teórico entre os ingressantes, o Grupo PET decidiu promover um questionário a ser preenchido após o evento. Este conteve questões relacionadas ao PET-Quiz e aos temas abordados, e os respondentes assinalaram como se sentiram em relação a cada abordagem. Em questões qualitativas, os questionados responderam utilizando uma escala numérica que varia de 0 (zero) a 4 (quatro) (Figura 2).

Figura 2 - Escala para avaliações qualitativas

$$
\begin{aligned}
& \text { - } 0 \text { - Péssima } \\
& \text { - } 1 \text { - Ruim } \\
& =2 \text { - Regular } \\
& =3 \text { - Bom } \\
& =4 \text { - Excel ente }
\end{aligned}
$$

Essa edição especial do PET-Quiz foi um evento aberto a todos os calouros ingressantes no curso de Engenharia Civil UFPA do ano de 2020. A pesquisa foi feita de forma totalmente online, uma vez que as informações de contato dos calouros participantes do evento estavam 
disponíveis. O questionário foi enviado aos 31 participantes, dos quais 29 retornaram com respostas.

Ao ter acesso aos dados de resposta, foi feita uma análise quantitativa, a fim de buscar atender ao objetivo da pesquisa. Com tais informações, planilhas e gráficos foram elaborados para o entendimento da eficácia do PET-Quiz em difundir os conhecimentos da Engenharia Civil entre os calouros.

\section{MÉTODOS DO QUIZ}

Previamente elaborada pelos graduandos participantes do grupo PET, a atividade foi direcionada aos calouros do curso de bacharelado em Engenharia Civil da UFPA do ano de 2020. Em formato de quiz, o evento contou com um total de 6 equipes e cada equipe dispunha de 5 a 6 integrantes. As questões da competição, foram de conhecimentos gerais e específicos da Engenharia Civil, das ênfases: Construção Civil, Estruturas Materiais, Geotecnia, Transportes e Hidrotecnia. A divisão foi feita em dois níveis de dificuldades, contando com um total de 72 questões, sendo 36 intuitivas e 36 específicas das disciplinas da grade curricular.

O quiz contou com três fases: Preliminar, Semifinal e Final. A fase Preliminar foi composta por 6 rodadas com 6 perguntas em cada uma, todas de conhecimentos intuitivos. As três equipes que mais pontuaram nesta fase, foram encaminhadas para a fase Semifinal, que dispôs de 4 rodadas com 6 perguntas em cada uma. Nesta etapa, já foram abordados conhecimentos específicos, assim como na fase Final, que foi concorrida pelas duas equipes que mais pontuaram na fase anterior. Com a metodologia de passa ou repassa, esta fase foi inteiramente dinâmica, pois as equipes finalistas tinham a oportunidade de responder aos questionamentos caso a equipe oponente falhasse, podendo assim, aferir ainda mais a busca pela assertividade e desenvolvendo maior atenção das equipes para os conhecimentos debatidos na competição.

\section{RESULTADOS E ANÁLISES}

Para analisar a eficiência do PET-Quiz em disseminar o conhecimento das ênfases do curso entre os novos ingressantes, os formulários para obtenção de dados continham questões elaboradas especificamente para a confecção deste artigo. Os participantes foram questionados tanto a respeito da apresentação das ênfases da graduação em Engenharia Civil quanto da eficiência da metodologia de disseminação de conteúdo (quiz competitivo) e da possível mudança de perspectiva futura com relação ao andamento do curso.

\subsection{Apresentação das ênfases do curso de Engenharia Civil da UFPA}

Com ênfases do curso entende-se as áreas da Engenharia Civil das quais a UFPA aborda com mais relevância, sendo elas, Construção Civil, Materiais, Estruturas, Geotecnia, Hidrotecnia e Transportes, as quais foram abordadas no PET-Quiz.

Para avaliar o impacto dessa estratégia de ensino, os participantes foram questionados a respeito do conhecimento acerca das temáticas abordadas antes e depois da atividade. Ao serem questionados a respeito das ênfases abordadas no PET-Quiz que eles já tinham conhecimento, obtivemos a seguinte resposta: 
Figura 3 - Resposta percentual à pergunta sobre conhecimentos pré-existentes

$\begin{aligned} \begin{array}{l}\text { Quais áreas da Engenharia Civil você NÃO conhecia antes } \\ \text { do PET-Quiz? }\end{array} & =\text { Hidrotecnia } \\ & =\text { Geotecnia } \\ & =\text { Estruturas } \\ & =\text { Materiais } \\ & =\text { Construção civil } \\ & =\text { Transportes }\end{aligned}$

Na presente pergunta, a qual poderia ser respondida com mais de uma opção, ilustrada pela Figura 3, percebeu-se que as áreas de Construção Civil e Estruturas são de conhecimento geral dentre os calouros, devido à ausência de seleção dessas áreas nas respostas.

Todos os alunos selecionaram pelo menos uma ênfase que desconheciam e dentre as 24 seleções de resposta, Hidrotecnia (37\%) e Transportes (29\%) foram as áreas mais selecionadas pelos alunos. Desse modo, a maioria dos alunos respondentes somente passou a ter conhecimento da totalidade das abrangências do curso após a participação no PET-Quiz.

Também foi questionado aos alunos sobre a área que mais lhes despertou interesse e as áreas de Construção Civil e Estruturas foram as mais selecionadas, com $38 \%$ e $46 \%$ das respostas, respectivamente. Isso é compreensível, uma vez que estas são as duas áreas do curso que os ingressantes geralmente conhecem antes de adentrá-lo. Isso pode ser percebido através da análise da Figura 3.

Independente da ausência de conhecimentos mais específicos acerca das áreas escolhidas, instigados pela atividade de caráter introdutório e ilustrativo, os alunos demonstram gostar dessas, o que pode interferir diretamente no desenvolvimento desses indivíduos ao longo do curso, bem como na própria escolha da área de atuação após a formação (DRUMMOND et al., 2009).

\subsection{Avaliação da metodologia de disseminação de conteúdo}

Também foram solicitadas, a fim de se fazer um apanhado geral do evento, respostas a respeito da metodologia ágil de apresentação - neste caso, um quiz no formato televisivo de programa de auditório.

Uma verificação interessante a ser feita se fundamenta em avaliar uma metodologia ativa, como a aplicação de um quiz, no quesito eficiência em apresentar novos conhecimentos. Para isso, os participantes foram questionados e sua resposta nos dá um parâmetro suficiente para tal análise (Figuras 4 e 5). 
Figura 4 - Resposta percentual à pergunta sobre a utilidade da dinâmica de perguntas e respostas para apresentação de novas áreas da Engenharia Civil.

\section{Você considera a dinâmica de perguntas e respostas útil para a apresentação de novas áreas? Avalie.}

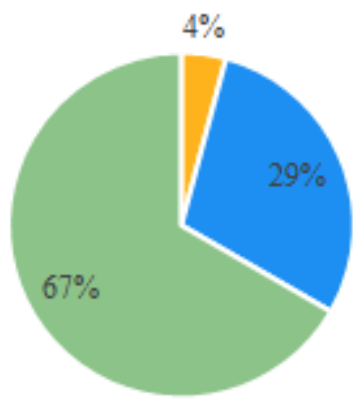

- 0 - Péssima

- 1 - Ruim

- 2 - Regular

- 3 - Bom

- 4 - Excelente

Figura 5 - Resposta percentual à pergunta sobre a abordagem dos assuntos tratados no PET-Quiz

Como você avalia a abordagem dos assuntos tratados?

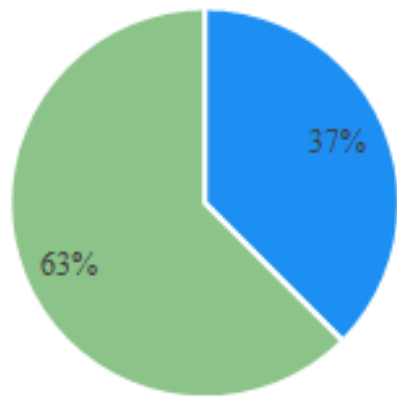

- 0 - Pés sima

- 1 - Ruim

- 2 - Regular

- 3 - Bom

- 4 - Excelente

Nota-se, a partir das Figuras 4 e 5, que a abordagem dos assuntos (a partir de vídeos e conteúdos interativos) e a dinâmica aplicada (quiz de perguntas e respostas) foram, de maneira geral, apreciadas pelos estudantes, uma vez que cerca de $98 \%$ das respostas das duas perguntas variam entre os conceitos "3 - Bom" e "4 - Excelente". Esse resultado é animador, tendo em vista que o PET-Quiz nunca havia sido utilizado para esse fim de apresentação. Vargas (2017) atribui essa avaliação à "competição" promovida pela metodologia ativa de quiz, que proporciona coleguismo, desenvolvimento do pensamento crítico e aumento do nível de concentração dos participantes.

Quanto aos conhecimentos adquiridos, os participantes apresentaram opiniões ligeiramente positivas. Durante o PET-Quiz, foram abordadas disciplinas dos diferentes semestres da graduação, bem como de áreas distintas, resultando em uma quantidade significativa de novas informações repassadas aos participantes. Diante disso, O Grupo PET minimizou as complicações advindas da necessidade de conhecimento técnico prévio, o que possibilitou a imersão plena dos calouros. Assim, 50\% dos entrevistados relataram como "4 Excelente" os conhecimentos adquiridos acerca do curso, enquanto $42 \%$ relataram como "3 Bom" e cerca de $8 \%$ dos entrevistados relataram como "2 - Regular". 
Quando questionados a respeito da intenção do Grupo PET Civil em apresentar o curso por meio da metodologia ativa de quiz de perguntas e respostas, $88 \%$ dos participantes julgaram como "4 - Excelente". Isso reforça a aceitação e a capacidade das metodologias ativas em envolver o aluno colocando-o como protagonista no seu processo de aprendizagem (MASETTO, 2014)

\subsection{Análise de mudança de perspectiva}

Esta análise leva em consideração as intenções dos novos ingressantes ao escolherem o curso de Engenharia Civil antes de terem qualquer contato com a universidade e suas percepções após participarem da competição.

Nesse sentido, é interessante perceber alguma alteração desse pensamento inicial, uma vez que novas ideias foram apresentadas e estas possibilitam um leque de atuações bastante diversificado. Porém, deve-se considerar o fato de que determinados novos ingressantes podem já ter tido acesso a algum tipo de conteúdo semelhante ao que foi ministrado no PET-Quiz. Por essa ótica, uma permanência de ideias é perfeitamente compreensível.

Ao serem questionados sobre a motivação em escolher o curso de graduação em Engenharia Civil, a principal motivação destacada estava relacionada à orientação vocacional ao prestar o vestibular, representando $62 \%$ dos entrevistados. Questões como piso salarial, influência familiar e jornada de trabalho também foram respostas, porém, menos significativas.

Quando abordados sobre uma possível mudança de perspectiva com relação à motivação da escolha do curso, 33\% relataram uma mudança de perspectiva, porém $67 \%$ dos entrevistados não apontaram mudanças de pensamento, independentemente do posterior esclarecimento acerca dos assuntos relacionados à Engenharia Civil. Isso demonstra certo conservadorismo acerca dessas perspectivas futuras, numa manutenção de ideias iniciais nesse primeiro momento. Ao se fazer uma análise mais aprofundada, resposta por resposta, constata-se que a orientação vocacional continua sendo a motivação majoritária dos ingressantes em Engenharia Civil da UFPA em 2020.

\section{CONSIDERAÇÕES FINAIS}

Diante da discussão apresentada, percebe-se que a dinâmica do PET-Quiz como meio para a apresentação do curso de modo amplo é efetiva, visto que a necessidade de conhecer o curso ao qual se adentra é fatídica e a análise de resultados evidencia a falta de conhecimento por parte dos calouros acerca da existência de algumas das ênfases do curso. Apresentar tais ênfases de maneira agradável aos ingressantes é uma maneira eficaz de introduzi-los à graduação.

Quanto à avaliação da metodologia de "Quiz" adotada, percebe-se sua aceitação pelos ingressantes por conta do grande percentual de "Excelente" e "Bom" recebidos. Isso confirma trabalhos anteriormente realizados referentes à aplicação de metodologias ativas na assimilação de conteúdos associada a dinâmicas mais divertidas.

Ademais, a consideração sobre mudança de perspectiva, demonstra que, no mínimo, conhecer as ênfases do curso permite que a ótica sob a qual o curso é visto pode ser alterada, apesar de não ser o principal fator de impacto nesse sentido. Desse modo, pode-se afirmar que o presente trabalho alcança o objetivo traçado sob o ponto de vista de avaliar a eficiência da atividade PET-Quiz em apresentar as ênfases do curso de Engenharia Civil e discutir a possibilidade de mudança de perspectiva com essa metodologia, além de possibilitar novas pesquisas nessa conjuntura. 


\section{REFERÊNCIAS}

BARROWS, H.; TAMBLYN, R. Problem-based learning: an approach to medical education. New York: Springer Publishing, 1980.

BRASIL. Ministério da Educação. Portaria n ${ }^{\circ}$ 976, de 27 de Julho de 2010. Diário Oficial da União, Poder Executivo, Brasília, 31 out. 2013. Seção 1, p. 40.

COIL, D. A.; ETTINGER, C. L.; EISEN, J. A. Gut Check: The evolution of an educational board game. PLoS Biology, Vol.15(4), p.e2001984. April 28, 2017.

CORDEIRO, J. S.; SERRA, S. M. B. A experiência da concepção em ênfases do curso de graduação em engenharia civil da UFSCAR. In: XXXII Congresso Brasileiro de Educação em Engenharia, 2004, Brasília. Anais. Brasília, 2004.

DRUMMOND, A.; MANCINI, M.; BUENO, K.; KLAUSING, K.; MOURA, L. Fatores que influenciam a escolha da área de atuação entre formandos em Terapia Ocupacional. Revista De Terapia Ocupacional Da Universidade De São Paulo, São Paulo, v.20 n.2, p. 68-74, 2009.

MASETTO, M. T. (Org.). Docência na universidade. Ebook. Campinas: Papirus, 2014.

MILTRE, S. M. et al., Metodologias ativas de ensino-aprendizagem na formação profissional em saúde: debates atuais. Ciência e Saúde Coletiva, Rio de Janeiro, v. 13, suppl. 2, 2008.

SANDE, D.; SANDE, D. Uso do kahoot como ferramenta de avaliação e ensino-aprendizagem no ensino de microbiologia industrial. HOLOS, Vol.34(1), pp.170-179, 2018.

SILVA, J. M. A.; CANEDO, R. V.; ABRANTES, T. A. S.; SANTOS, R. T.; SOUZA, R. A.; UTAGAWA, C. Y. Quiz: um questionário eletrônico para autoavaliação e aprendizagem em genética e biologia molecular. Revista Brasileira de Educação Médica, Vol.34(4), pp.607-614, 01 December 2010.

VARGAS, D. O processo de aprendizagem e avaliação através de QUIZ. 2017. Universidade do Vale do Taquari - Univates, Lajeado, 22 set. 2017. Disponível em: <http://hdl.handle.net/10737/2038>.

\section{PET-QUIZ AS A KNOWLEDGE SPREADER ABOUT THE SUB-DISCIPLINES APPROACHED BY CIVIL ENGINEERING GRADUATION}

Abstract: This study presents a semiannual competition prepared by the Tutorial Education Program (PET) Civil Engineering at UFPA, called PET-Quiz, which deals with general knowledge of engineering in a dynamic of questions and answers, with the intention of presenting the sub-disciplines of Civil Engineering to freshmen from the beginning of the course, transcending the formal education environment, in order to stimulate the development 
of skills, which include the development of critical thinking, communication and collaboration. In its 4th edition, it presented a new format, with simplified language, differentiated vibe and dynamics, aiming to follow the television genre of auditorium program, idealized so that students could compete in an animated way in teams. Through a drawing, the teams answered questions about the main sub-disciplines of engineering: Civil Construction, Structures, Materials, Geotechnics, Transport and Hydrotechnics. At the end of the competition, the teams were encouraged to complete an online form, which had as main objective to analyze the impact of the PET-Quiz on previous knowledge about the areas targeted by the course, as well as the possible change of perspective of students in pretexts of their academic training. With such data, it was possible to analyze the efficiency of the PET-Quiz in the dissemination of theoretical knowledge about the main areas of the course to freshmen, which proved to be effective. It is also noticed that the perspectives that the participants once had in relation to entering graduation changed by a portion of the interviewees.

Key words: Civil Engineering. Integration. Active Methodology. Tutorial Education Program. 